\title{
Antitumor effects of inductive hyperthermia using magnetic ferucarbotran nanoparticles on human lung cancer xenografts in nude mice
}

This article was published in the following Dove Press journal:

OncoTargets and Therapy

23 March 2013

Number of times this article has been viewed

\author{
Tomoyuki Araya' \\ Kazuo Kasahara' \\ Shingo Nishikawa' \\ Hideharu Kimura' \\ Takashi Sone' \\ Hideo Nagae ${ }^{2}$ \\ Yoshio Ikehata $^{3}$ \\ Isamu Nagano ${ }^{3}$ \\ Masaki Fujimura' \\ 'Department of Respiratory \\ Medicine, Cellular Transplantation \\ Biology, Kanazawa University \\ Graduate School of Medical Science, \\ ${ }^{2}$ Cooperative Research Center for \\ Kanazawa University, ${ }^{3}$ Department of \\ Information and Systems Engineering, \\ Kanazawa University, Kanazawa, Japan
}

Correspondence: Kazuo Kasahara Department of Respiratory Medicine, Cellular Transplantation Biology, Kanazawa University Graduate School of Medical Science, I3-I Takara-machi, Kanazawa 920-864I, Japan

Tel +8I 762652273

Fax +8I 762344252

Email kasa1237@gmail.com
Background: The effects of inductive hyperthermia on lung cancer have yet to be fully investigated. Magnetic nanoparticles used in inductive hyperthermia are made-to-order and expensive. This study was performed to investigate the use of ferucarbotran in inductive hyperthermia and to clarify whether inductive hyperthermia using ferucarbotran promotes antitumor effects in vivo using a lung cancer cell line.

Methods: We injected A549 cells subcutaneously into the right thighs of BALB/c nu/nu nude mice. Forty mice with A549 xenografts were then classified into three groups. Group 1 was the control group. All mice in groups 2 and 3 had ferucarbotran injected into their tumors, and mice in group 3 were then subjected to alternating magnetic field irradiation. We evaluated tumor temperature during the hyperthermic procedure, the time course of tumor growth, histologic findings in tumors after hyperthermic treatment, and adverse events.

Results: Intratumor temperature rose rapidly and was maintained at $43^{\circ} \mathrm{C}-45^{\circ} \mathrm{C}$ for 20 minutes in an alternating magnetic field. Tumor volumes in groups 1 and 2 increased exponentially, but tumor growth in group 3 was significantly suppressed. No severe adverse events were observed. Histologic findings for the tumors in group 3 revealed mainly necrosis.

Conclusion: Inductive hyperthermia using ferucarbotran is a beneficial and promising approach in the treatment of lung cancer. Ferucarbotran is a novel tool for further development of inductive hyperthermia.

Keywords: inductive hyperthermia, ferucarbotran, magnetic nanoparticles, alternating magnetic field, lung cancer, human use

\section{Introduction}

Hyperthermia is a promising approach in the treatment of cancer, and various methods have been adopted, including whole body hyperthermia, ${ }^{1}$ radiofrequency hyperthermia, ${ }^{2}$ and induced hyperthermia using a microwave antenna ${ }^{3}$ or implantable needles. ${ }^{4}$ However, an inevitable technical problem with hyperthermia is the difficulty of uniformly heating only the tumor region to the required temperature without damaging healthy tissues. Therefore, some researchers have proposed inductive hyperthermia using submicron magnetic particles. ${ }^{5,6}$

The dextran magnetite complex is a submicron magnetic particle that consists mainly of magnetic nanoparticles coated with dextran which generate heat in an alternating magnetic field by both Brownian and Néel relaxation. ${ }^{7,8}$ These magnetic nanoparticles have been widely studied to improve adsorption activity, heat-generating efficiency, and accumulation in tumor cells due to electrostatic interaction with the cell membrane. ${ }^{6-9-11}$ Although excellent magnetic nanoparticles overcoming these 
difficulties have emerged, they are made-to-order and expensive. ${ }^{6}$ Therefore, more practical magnetic nanoparticles are currently in demand.

In this study, we used ferucarbotran, a magnetic resonance imaging contrast agent reported to be able to generate heat in an alternating magnetic field. ${ }^{12-15}$ Although there have been numerous studies on the effects of inductive hyperthermia in various cancers, ${ }^{10,16,17}$ the effects on lung cancer have yet to be investigated fully. In this study, we performed animal experiments using nude mice with lung cancer xenografts for the following purposes: to reconfirm that commercially available ferucarbotran can generate heat in an alternating magnetic field and to clarify whether inductive hyperthermia using ferucarbotran exerts antitumor effects on lung cancer xenografts.

\section{Materials and methods}

\section{Ferucarbotran}

Ferucarbotran consists mainly of a hydrophilic colloidal solution of superparamagnetic iron oxide coated with carboxydextran. It is a complex composed of ultrafine $(7 \mathrm{~nm}$ diameter) magnetite particles and alkali-treated dextran. ${ }^{6}$ Ferucarbotran, which is inexpensive and readily available (Nihon Schering KK, Osaka, Japan) is typically used in medical practice as a magnetic resonance imaging contrast agent (Resovist ${ }^{\circledR}$ one vial, $1.6 \mathrm{~mL}$; ferucarbotran, $540 \mathrm{mg} / \mathrm{mL}$; $27.9 \mathrm{mg} \mathrm{Fe} / \mathrm{mL}$ or $496 \mu \mathrm{mol} \mathrm{Fe} / \mathrm{mL}) .{ }^{18}$

\section{Cell line}

The human A549 non-small cell lung cancer cell line was used in this study. The A549 cells were obtained from the American Type Culture Collection, maintained in RPMI-1640 medium supplemented with 10\% fetal bovine serum, $5 \mathrm{mM}$ nonessential amino acids, and antibiotics (penicillin $100 \mathrm{U} / \mathrm{mL}$ and streptomycin $100 \mu \mathrm{g} / \mathrm{mL}$ ) at $37^{\circ} \mathrm{C}$ in a $5 \% \mathrm{CO}_{2}$ and $95 \%$ air incubator, and subcultured by harvesting with trypsin-EDTA.

\section{Development of xenografts}

All animal experiments were approved by the Animal Care and Use Committee of Kanazawa University. Forty BALB/c nu/nu athymic female nude mice aged 4 weeks and weighing approximately $20 \mathrm{~g}$ were used in this study, and were purchased from Sankyo Laboratory Service (Toyama, Japan). All mice were injected with cell suspensions, consisting of approximately $1 \times 10^{7}$ cells in $0.1 \mathrm{~mL}$ of phosphatebuffered saline, subcutaneously into the right thigh. When the maximum diameter of the tumors reached $10 \mathrm{~mm}$ after transplantation, the hyperthermic experiments were started. All mice were randomly divided into three groups. Group 1 $(n=16)$ was the control group without treatment. Mice in group $2(n=8)$ had ferucarbotran injected into their tumors without alternating magnetic field irradiation. Mice in group 3 ( $n=16$ ) were injected with ferucarbotran and subjected to alternating magnetic field irradiation once only. A smaller number of mice were assigned to group 2 because the safety of ferucarbotran alone has already been established. ${ }^{13,18-20}$ Tumor volumes (V) were measured three times per week and calculated using the formula: $\mathrm{V}=\pi / 6 \times$ larger diameter $\times(\text { smaller diameter })^{2}$, as reported previously. ${ }^{21}$ Tumor volumes were evaluated for one month after the start of hyperthermic treatment.

\section{Inductive hyperthermia}

All procedures in animals were performed under anesthesia using 2\% pentobarbital sodium (Nembutal ${ }^{\circledR}$, Dainippon Sumitomo Pharma, Osaka, Japan) administered by intraperitoneal injection $(50 \mathrm{mg} / \mathrm{kg}$ ). Reportedly, the lethal dose of ferucarbotran solution in mice is more than $10 \mathrm{mmol}$ $\mathrm{Fe} / \mathrm{kg}$ (558 mg Fe/kg; Resovist $20 \mathrm{~mL} / \mathrm{kg}) .{ }^{13}$ Ferucarbotran was injected into the core of the tumors in all mice only once, immediately before alternating magnetic field irradiation at a dose of $150 \mu \mathrm{L}$, which is equivalent to Resovist $7.5 \mathrm{~mL} / \mathrm{kg}$. A newly developed powerful induction heating device comprising a high-frequency power source and an applicator (Figure 1A) $)^{13}$ was then used to generate an alternating current $142 \mathrm{kHz}$ magnetic field from an electric
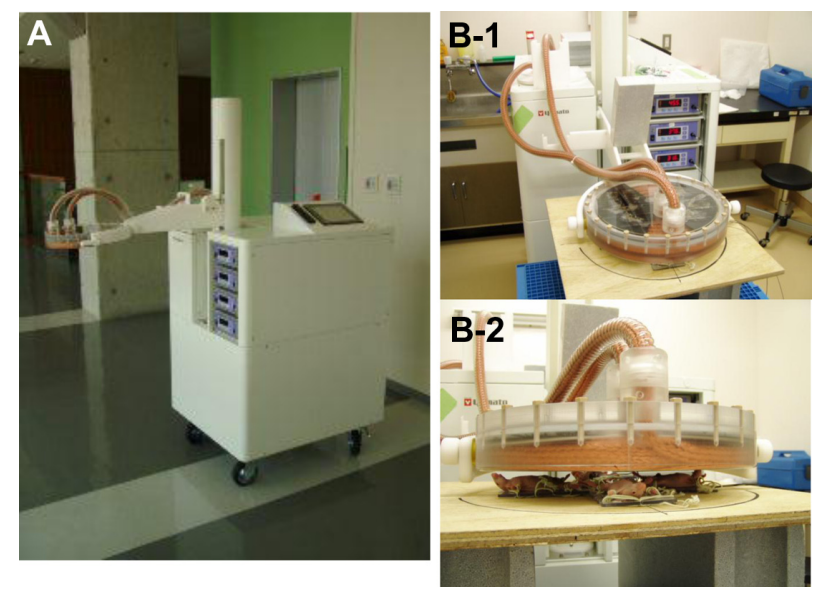

Figure I Portable induction heating device. (A) Dimensions are height $173 \mathrm{~cm}$, width $73 \mathrm{~cm}$, and length $83 \mathrm{~cm}$; weight is $150 \mathrm{~kg}$, and it has a wheel carriage. (B-I) It is composed of a high-frequency power source and an applicator, which creates an alternating current $142 \mathrm{kHz}$ magnetic field from an electric current in a pancake coil. (B-2) The center of the tumor in each mouse was $2 \mathrm{~cm}$ distant from the surface of the applicator.

Note: The strength of the magnetic field is $20-24 \mathrm{mTesla}$ at this position. 
current (maximum 440 amps) in a pancake coil (diameter $240 \mathrm{~mm}$; five turns). The power consumption of this device is $3.5 \mathrm{~kW}$ with use of a single-phase alternating current $200 \mathrm{~V}$ (Figure 1B-1). For safe use in humans, this device adheres to the guidelines of the International Commission on Non-Ionizing Radiation Protection for limiting exposure to time-varying electric, magnetic, and electromagnetic fields at a distance of $1.5 \mathrm{~m}$ from the applicator. ${ }^{22}$ We set the surface of the applicator $2 \mathrm{~cm}$ from the center of the tumor in each mouse. The strength of the magnetic field is 20-24 mTesla at this position (Figure 1B-2). Under these conditions, temperatures in the peripheral regions of the tumors (distant side to rectum) were measured using an optical fiber thermometer (FL-2000, Anritsu Meter Co, Ltd, Tokyo, Japan) during the hyperthermic procedures. At the same time, rectal temperatures were monitored to reflect normal tissue temperature. The rationale for hyperthermia is based on the direct cellkilling effects observed at temperatures above $42.5^{\circ} \mathrm{C},{ }^{23}$ so intratumor temperature was adjusted to $43^{\circ} \mathrm{C}-45^{\circ} \mathrm{C}$ for 20 minutes in the alternating magnetic field to avoid overheating or underheating. We evaluated tumor size and observed any adverse events of inductive hyperthermia for 28 days after the start of hyperthermic treatment.

\section{Histologic examination}

On day 7 following hyperthermic treatment, two mice in each group were euthanized for histologic examination. The tumors were resected, fixed with $10 \%$ formalin solution, and sectioned longitudinally. Tumor specimens were stained with hematoxylin and eosin, and the condition of the cells around ferucarbotran was subsequently evaluated. Following staining with hematoxylin and eosin, tumor specimens from all groups were examined for apoptosis by a TUNEL (TdT-mediated dUTP-biotin nick-end labeling) assay using the DeadEnd ${ }^{\mathrm{TM}}$ Colorimetric TUNEL system (Promega, Madison, WI, USA), in accordance with the manufacturer's instructions. Apoptosis was evaluated using the apoptotic index, as reported previously. ${ }^{24}$ Briefly, 500 cells were counted in each specimen, and the apoptosis index was defined as:

Apoptotic index $(\%)=100 \times$ apoptotic cells/total cells.

\section{Statistical analysis}

The statistical analysis was performed using Statview version 5.0 software (SAS Institute Inc, Cary, NC, USA). The statistical significance of tumor growth between the three groups was evaluated using the Mann-Whitney $U$ test. $P<0.05$ was considered to be statistically significant.

\section{Results}

\section{Antitumor effects of inductive hyperthermia}

The time course of tumor growth in each group is shown in Figure 2. Tumor volumes in groups 1 and 2 increased exponentially with no regression, and no significant differences were observed between tumor volumes on day 28 in groups 1 and $2(P=0.517)$. Tumor volume on day 28 after treatment in group 3 was significantly suppressed when compared with that in groups 1 and 2 (group 1 versus group 3, $P=0.0002$; group 2 versus group $3, P=0.016)$. However, complete tumor suppression was not observed in group 3.

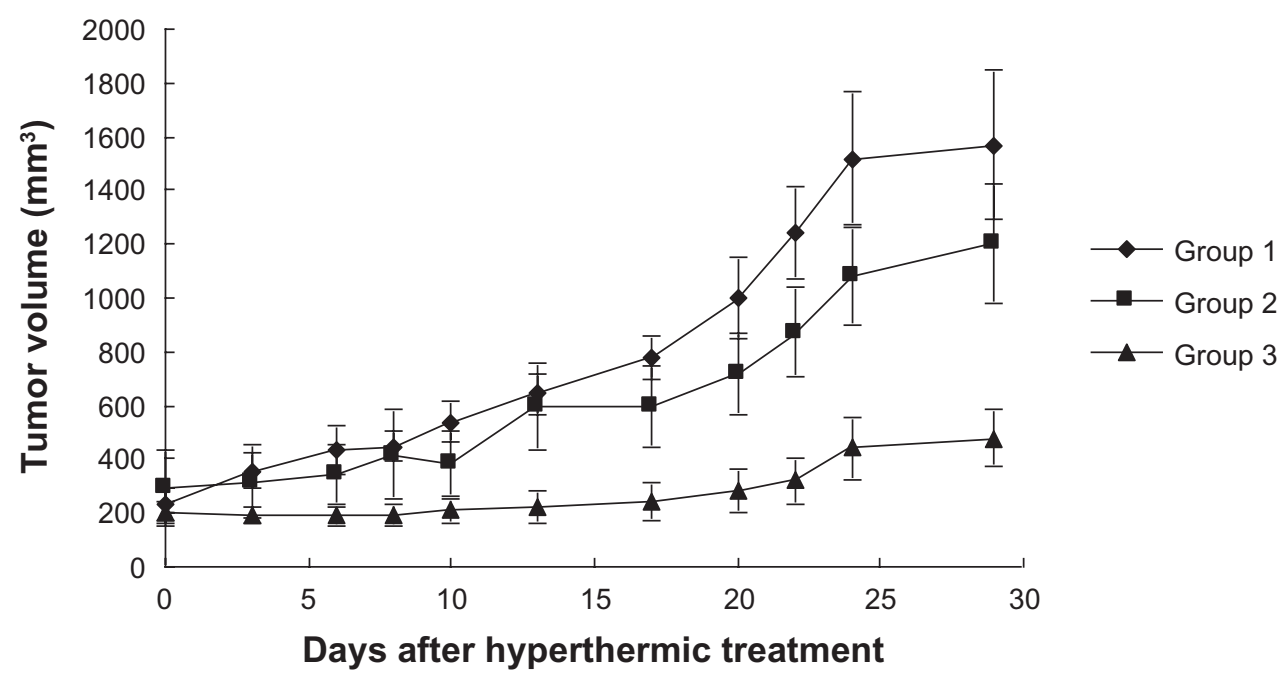

Figure 2 Time courses of tumor growth in each therapeutic group.

Note: Data points and error bars indicate means and standard errors of tumor volumes for all xenografts in each therapeutic group. 


\section{Measurement of temperature}

To evaluate the selectivity of heating in our hyperthermic treatment, the temperatures in both tumor and normal tissue (rectum) were measured. Intratumor and rectal temperatures during the hyperthermic procedures are shown in Figure 3. Intratumor temperature in group 3 rose rapidly and reached over $43^{\circ} \mathrm{C}$ within 2.5 minutes. The temperature was maintained at $43^{\circ} \mathrm{C}-45^{\circ} \mathrm{C}$ for 20 minutes in an alternating magnetic field. In contrast, rectal temperatures did not increase in an alternating magnetic field.

\section{Histologic findings}

Representative microscopic findings for the tumor cells in each group are shown in Figure 4. Hematoxylin and eosin staining of tumor cells around ferucarbotran in group 3 revealed broad necrosis after hyperthermic treatment (Figure 4C), whereas tumor cells in groups 1 and 2 showed no necrosis (Figure 4A and B). Representative TUNEL staining of tumor cells in each group is shown in Figure 5. The positive control for TUNEL staining (tumor cells treated with DNase) is shown in Figure 5A. Few tumor cells were positive for TUNEL staining in groups 1 and 2 (Figure 5B and C). The apoptotic index in groups 1 and 2 was $1.78 \% \pm 0.66 \%$ and $1.72 \% \pm 0.79 \%$, respectively. Further, the apoptotic index in group 3 was $2.42 \% \pm 0.85 \%$, similar to groups 1 and 2 in TUNEL staining (Figure 5D). There was no significant difference between groups 1,2 , and $3(P>0.05)$. These findings suggest that inductive hyperthermia using ferucarbotran causes mainly necrosis but not apoptosis in tumor cells.

\section{Adverse events}

No treatment-related deaths or toxicities related to injection of ferucarbotran were reported. Three of 14 mice in group 3 showed a transient decrease in body weight, but no severe adverse events, such as ulcers in the region of heating, growth impairment, or loss of a leg, were observed. No adverse events were seen in animals from groups 1 or 2 .

\section{Discussion}

We demonstrated the activity and safety of inductive hyperthermia using clinically available ferucarbotran in the treatment of lung cancer xenografts in an in vivo model. Our results indicate that inductive hyperthermia using ferucarbotran stably heated the whole tumor to approximately $45^{\circ} \mathrm{C}$ during most of the treatment period (Figure 3), and subsequently induced mainly necrosis of tumor cells, as reported previously. ${ }^{25,26}$ Hyperthermia at temperatures above $44^{\circ} \mathrm{C}$ has been reported to cause necrosis of tumor cells. ${ }^{25,26}$ Further similar results have been reported in inductive hyperthermia models in vivo. Takamatsu et $\mathrm{al}^{13}$ reported that induction heating using ferucarbotran did not increase apoptosis in treated tumor cells, and Wang et $\mathrm{al}^{27}$ reported that most tumor cells heated to a higher temperature became necrotic in response to inductive hyperthermia, as we demonstrated in this study. In contrast, normal tissues without ferucarbotran were not heated in an alternating magnetic field. These findings indicate stable, efficient, and selective heating by inductive hyperthermia using ferucarbotran.

The safety and permissible dose of ferucarbotran in medical practice has already been established. ${ }^{18-20}$ Although there are numerous magnetic nanoparticles used in inductive hyperthermic experiments, most of them are not approved for human use, and only a few safe magnetic nanoparticles, such as ferumoxides (Feridex ${ }^{\circledR}$, AMAG Pharmaceuticals Inc, Lexington, MA, USA), have been developed for medical practice. Although the ferumoxides approved as a magnetic resonance imaging contrast agent produce heat in an alternating magnetic field, we confirmed that the heat-generating

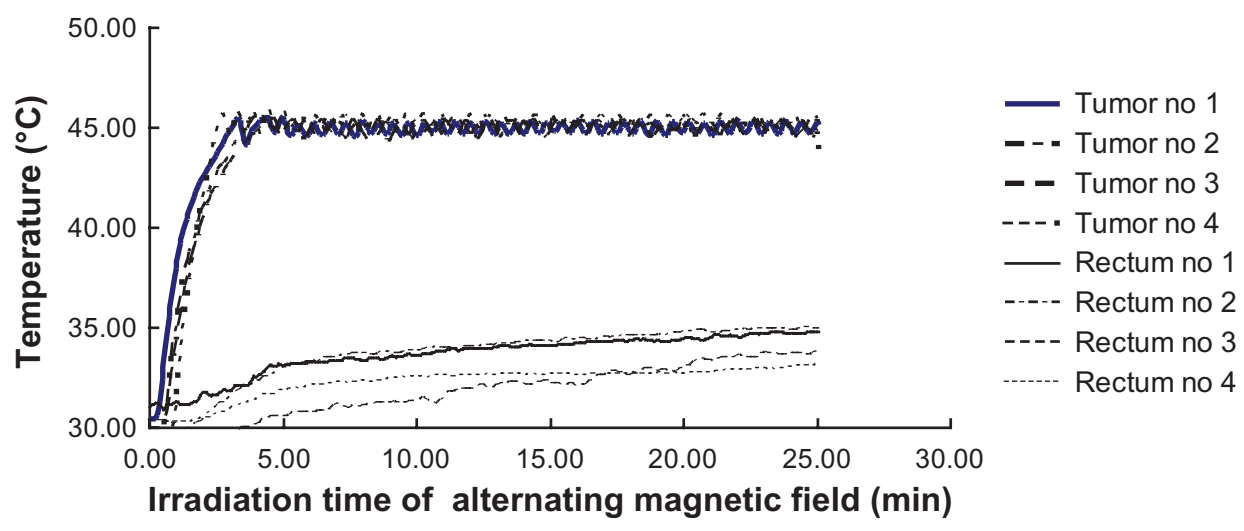

Figure 3 Time courses of intratumoral temperature for four representative xenografts in group 3. Note: Bold lines indicate intratumoral temperatures and thin lines indicate rectal temperatures. 


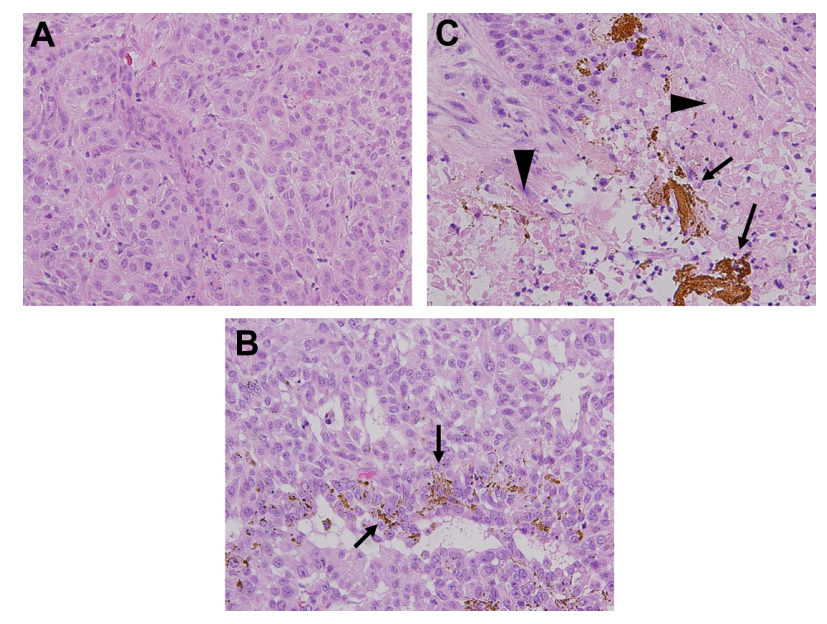

Figure 4 Microscopic appearances of tumor specimens. (A and B) Necrosis was not induced in tumors in group 1 or 2 (hematoxylin and eosin staining, $\times 200$ ). (C) Ferucarbotran was injected into tumors (arrows) and tumor cells around ferucarbotran in group 3 showed broad necrosis after inductive hyperthermia (arrowheads, hematoxylin and eosin staining, $\times 200$ field).

efficiency of ferucarbotran in an alternating magnetic field was superior to that of ferumoxides in a preliminary in vitro study (data not shown). Therefore, we consider that inductive hyperthermia using ferucarbotran is a beneficial and feasible hyperthermic approach.

Experimental and clinical studies have indicated that heat plays a crucial role in human lung cancer. ${ }^{28-30}$ However, despite promising results, hyperthermia has yet to be established as a routine clinical treatment due to lack of availability of safe magnetic nanoparticles and techniques for clinical hyperthermia. The effects of inductive hyperthermia on lung cancer xenografts have been investigated, and reported to
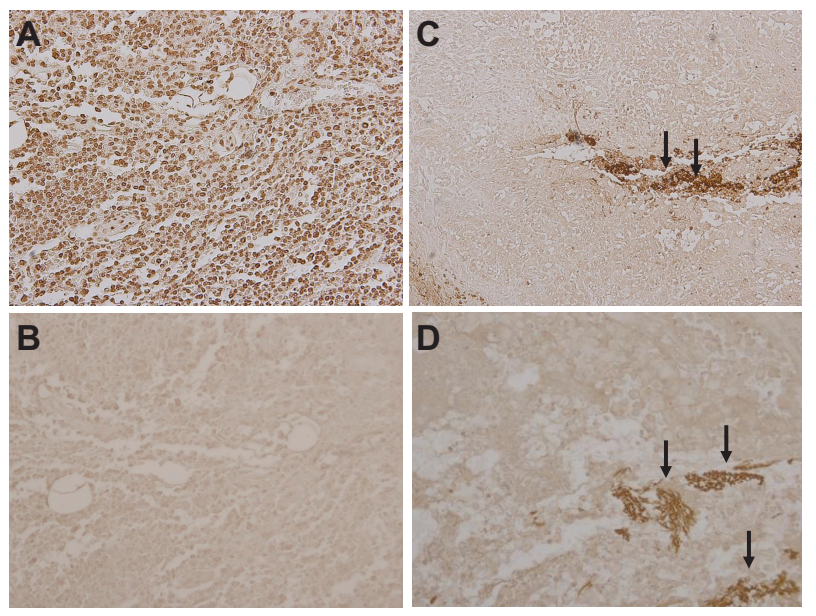

Figure 5 TUNEL staining of tumors in each group. (A) Positive control for TUNEL staining. Brown staining cells indicate TUNEL-positive cells, (B) group I, and (C) group 2. Irradiation of alternating magnetic field alone or injection of ferucarbotran alone did not induce apoptosis in lung cancer cells. (D) In group 3, inductive hyperthermia did not increase apoptotic cells around ferucarbotran (arrows) compared with groups I or 2 (TUNEL staining $\times 200$ field). be promising by $\mathrm{Hu}$ et al. ${ }^{28,29}$ However, the magnetic nanoparticles used in their studies were approved for laboratory use, but not for human use. Inductive hyperthermia using clinically available ferucarbotran had marked antitumor effects on lung cancer xenografts, and the effectiveness of our hyperthermia strategy was similar to that of previous studies using magnetic nanoparticles for laboratory use.

Moreover, we used not only ferucarbotran in this study, but also a powerful and safe induction heating machine developed for human use. ${ }^{13}$ Our results strongly suggest that inductive hyperthermic treatment using a combination of clinically available and safe ferucarbotran and machines has the potential for application in clinical settings. To develop inductive hyperthermia for lung cancer further, we need to deliver ferucarbotran to target tumor sites selectively using clinically available techniques. One possible solution to this problem is delivery of ferucarbotran to the feeding arteries of tumors using transcatheter arterial embolization, as previously reported. ${ }^{13}$ Furthermore, computed tomographyguided percutaneous injection of ferucarbotran or endobronchial ultrasound-guided transbronchial injection into target tumors using bronchoscopy can be used to assess the exact location of the ferucarbotran injection. These techniques may enable delivery of ferucarbotran selectively to target tumor sites.

Finally, despite the satisfactory antitumor effects and many advantages of ferucarbotran, complete tumor suppression was not observed in this study. In previous studies, tolerable hyperthermia alone was reported to be insufficient for complete suppression of tumors, ${ }^{27,31}$ so combination therapy with hyperthermia is necessary for complete tumor suppression. We are continuing our search for suitable drugs to use concomitantly with inductive hyperthermia and ferucarbotran to enhance the antitumor effects.

This study has several limitations. First, we only heated the tumors to $45^{\circ} \mathrm{C}$ to avoid thermal damage to other organs, particularly in an animal as small as the nude mouse. Therefore, the effects of induction heating at higher temperatures are unknown. Second, the surface of the induction heating applicator was set at $2 \mathrm{~cm}$ from the target lesions, which is too superficial to reflect deep organ cancers in adult humans in clinical practice. Further investigation is needed to confirm the effectiveness and safety of this method in the treatment of lung cancer in humans.

\section{Conclusion}

Inductive hyperthermia using ferucarbotran is a beneficial and promising approach in the treatment of lung cancer. 
Ferucarbotran is a novel tool needing further development in inductive hyperthermia.

\section{Disclosure}

The authors report no conflicts of interest in this work.

\section{References}

1. Baba H, Stephens LC, Strebel FR, et al. Protective effect of ICRF-187 against normal tissue injury induced by adriamycin in combination with whole body hyperthermia. Cancer Res. 1991;51(13):3568-3577.

2. Ikeda N, Hayashida O, Kameda H, Ito H, Matsuda T. Experimental study on thermal damage to dog normal brain. Int $J$ Hyperthermia. 1994;10(4):553-561.

3. Lin JC, Wang YJ. Interstitial microwave antennas for thermal therapy. Int J Hyperthermia. 1987;3(1):37-47.

4. Stauffer PR, Cetas TC, Fletcher AM, et al. Observations on the use of ferromagnetic implants for inducing hyperthermia. IEEE Trans Biomed Eng. 1984;31(1):76-90.

5. DeNardo SJ, DeNardo GL, Miers LA, et al. Development of tumor targeting bioprobes ((111)In-chimeric L6 monoclonal antibody nanoparticles) for alternating magnetic field cancer therapy. Clin Cancer Res. 2005;11(19):7087s-7092s.

6. Jordan A, Wust P, Fähling H, John W, Hinz A, Felix R. Inductive heating of ferrimagnetic particles and magnetic fluids: physical evaluation of their potential for hyperthermia. Int J Hyperthermia. 1993;9(1): 51-68.

7. Fannin PC. Magnetic spectroscopy as an aide in understanding magnetic fluids. J Magn Magn Mater. 2002;252:59-64.

8. Ma M, Wu Y, Zhou J, Sun Y, Zhang Y, Gu N. Size dependence of specific power absorption of $\mathrm{Fe} 3 \mathrm{O} 4$ particles in AC magnetic field. J Magn Magn Mater. 2004;268:33-39.

9. Shinkai M, Yanase M, Honda H, Wakabayashi T, Yoshida J, Kobayashi T. Intracellular hyperthermia for cancer using magnetite cationic liposomes: in vitro study. Jpn J Cancer Res. 1996;87(11):1179-1183.

10. Mitsumori M, Hiraoka M, Shibata T, et al. Targeted hyperthermia using dextran magnetite complex: a new treatment modality for liver tumors. Hepatogastroenterology. 1996;43(12):1431-1437.

11. Hilger I, Fruhauf K, Andra W, Hiergeist R, Hergt R, Kaiser WA. Heating potential of iron oxides for therapeutic purposes in interventional radiology. Acad Radiol. 2002;9(2):198-202.

12. Mitsumori M, Hiraoka M, Shibata T, et al. Development of intra-arterial hyperthermia using a dextran-magnetite complex. Int J Hyperthermia. 1994;10(6):785-793.

13. Takamatsu S, Matsui $\mathrm{O}$, Gabata T, et al. Selective induction hyperthermia following transcatheter arterial embolization with a mixture of nano-sized magnetic particles (ferucarbotran) and embolic materials: feasibility study in rabbits. Radiat Med. 2008;26(4):179-187.

14. Yamada K, Oda T, Hashimoto S, et al. Minimally required heat doses for various tumour sizes in induction heating cancer therapy determined by computer simulation using experimental data. Int $J$ Hyperthermia. 2010;26(5):465-474.

15. Murase K, Oonoki J, Takata H, et al. Simulation and experimental studies on magnetic hyperthermia with use of superparamagnetic iron oxide nanoparticles. Radiol Phys Technol. 2011;4(2):194-202.

OncoTargets and Therapy

\section{Publish your work in this journal}

OncoTargets and Therapy is an international, peer-reviewed, open access journal focusing on the pathological basis of all cancers, potential targets for therapy and treatment protocols employed to improve the management of cancer patients. The journal also focuses on the impact of management programs and new therapeutic agents and protocols on

Submit your manuscript here: http://www.dovepress.com/oncotargets-and-therapy-journa
16. Johannsen M, Gneveckow U, Eckelt L, et al. Clinical hyperthermia of prostate cancer using magnetic nanoparticles: presentation of a new interstitial technique. Int J Hyperthermia. 2005;21(7):637-647.

17. Ito A, Tanaka K, Honda H, Abe S, Yamaguchi H, Kobayashi T. Complete regression of mouse mammary carcinoma with a size greater than $15 \mathrm{~mm}$ by frequent repeated hyperthermia using magnetite nanoparticles. J Biosci Bioeng. 2003;96(4):364-369.

18. Reimer P, Balzer T. Ferucarbotran (Resovist): a new clinically approved RES-specific contrast agent for contrast-enhanced MRI of the liver: properties, clinical development, and applications. Eur Radiol. 2003;13(6):1266-1276.

19. Hamm B, Staks T, Taupitz M, et al. Contrast-enhanced MR imaging of liver and spleen: first experience in humans with a new superparamagnetic iron oxide. J Magn Reson Imaging. 1994;4(5):659-668.

20. Hirohashi S, Ichikawa T, Tanimoto A, et al. Dose investigation of superparamagnetic iron oxide (SPIO) SH U 555 A in liver MR imaging. Nippon Igaku Hoshasen Gakkai Zasshi. 2003;63(9):539-550. Japanese.

21. Ciardiello F, Bianco R, Damiano V, et al. Antitumor activity of sequential treatment with topotecan and antiepidermal growth factor receptor monoclonal antibody C225. Clin Cancer Res. 1999;5(4):909-916.

22. International Commission on Non-Ionizing Radiation Protection. Guidelines for limiting exposure to time-varying electric, magnetic, and electromagnetic fields (up to $300 \mathrm{GHz}$ ); ICNIRP guidelines. Health Phys. 1998;74:494-522.

23. Dewey WC, Hopwood LE, Sapareto SA, Gerweck LE. Cellular responses to combinations of hyperthermia and radiation. Radiology. 1977;123(2):463-474.

24. Magistrelli P, Coppola R, Tonini G, et al. Apoptotic index or a combination of Bax/Bcl-2 expression correlate with survival after resection of pancreatic adenocarcinoma. J Cell Biochem. 2006;97(1):98-108.

25. Ito A, Honda K, Kobayashi T. Cancer immunotherapy based on intracellular hyperthermia using magnetite nanoparticles: a novel concept of "heat-controlled necrosis" with heat shock protein expression. Cancer Immunol Immunother. 2006;55(3):320-328.

26. Yonezawa M, Otsuka T, Matsui N, et al. Hyperthermia induces apoptosis in malignant fibrous histiocytoma cells in vitro. Int $J$ Cancer. 1996;66(3):347-351

27. Wang L, Dong J, Ouyang W, Wang X, Tang J. Anticancer effect and feasibility study of hyperthermia treatment of pancreatic cancer using magnetic nanoparticles. Oncol Rep. 2012;27(3):719-726.

28. Hu R, Ma S, Li H, et al. Effect of magnetic fluid hyperthermia on lung cancer nodules in a murine model. Oncol Lett. 2011;2(6):1161-1164.

29. Hu R, Zhang X, Liu X, et al. Higher temperature improves the efficacy of magnetic fluid hyperthermia for Lewis lung cancer in a mouse model. Thorac Cancer. 2012;3:34-39.

30. Jiang Z, Yan W, Ming J, et al. Docetaxel weekly regimen in conjunction with RF hyperthermia for pretreated locally advanced non-small cell lung cancer: a preliminary study. BMC Cancer. 2007;7:189.

31. Hei TK, Hall EJ, Kushner S, Osmak RS. Hyperthermia, chemotherapeutic agents and oncogenic transformation. Int J Hyperthermia. 1986;2(3):311-320.

patient perspectives such as quality of life, adherence and satisfaction The manuscript management system is completely online and includes a very quick and fair peer-review system, which is all easy to use. Visit $\mathrm{http}: / /$ www.dovepress.com/testimonials.php to read real quotes from published authors. 